\title{
The Pattern of Breast Diseases at Kenyatta National Hospital
}

E.S. Otieno, MBChB, MMed (Surg), PGDRM (UoN), Lecturer, Department of Medical Physiology, College of Health Sciences, University of Nairobi, S.K. Kimende MBChB, MMed (Surg), Lecturer, Department of Surgery, College of Health Sciences, University of Nairobi and J. Micheni, MBChB. MMed (Surg), Consultant Surgeon, Kenyatta National Hospital, P. O. Box 30197-00100, Nairobi, Kenya

Correspondence and reprint requests to:

Dr. E.S. Otieno, Department of Medical Physiology, College of Health Sciences, University of Nairobi, P. O. Box 30197-00100, Nairobi, Kenya, Email: oedwin6@yahoo.com

\section{Abstract}

OBJECTIVE: To determine the pattern of breast diseases.

DESIGN: Retrospective descriptive study.

SETTING: Kenyatta National Hospital (KNH), a University Teaching and National Referral Hospital.

PATIENTS: One thousand one hundred and seventy two patients records were reviewed.

RESULTS: An average 469 new patients per year or 11 new patients per clinic visit were reviewed over a two and a half year period. Females predominated (98.9\%). The mean age of the patients was 34.71 years (range 1 to 96 years). The average age at menarche was 14.49 years and the mean duration of symptoms was 6.86 months. Only $2.6 \%$ of 843 patients had a positive family history of breast disease. Fibroadenoma was the commonest diagnosis made $(33.2 \%)$ followed by ductal carcinoma (19.7\%). Gynaecomastia was the most common lesion seen in males. Two thirds of patients presenting with lumps had masses measuring more than $5 \mathrm{~cm}$. Overall, five conditions (fibroadenoma, ductal carcinoma, breast abscesses, fibrocystic disease and mastalgia) accounted for over $85 \%$ of all breast ailments. Surgery formed the mainstay of care in over $80 \%$ of patients.

CONCLUSIONS: The pattern of breast diseases at $\mathrm{KNH}$ closely mirrors those reported in literature. This study indicates that a large proportion of patients presenting with breast diseases are treated initially by surgery. It may be wise to consider other alternative forms of therapy where appropriate.

\section{Introduction}

Epidemiological studies reveal wide disparities in the frequency and distribution of breast ailments across the world (1-3). When local breast disease distribution patterns are known, generalizations pertaining to diagnosis and management can be made with a reasonable degree of certainty. In addition, resource allocation and planning can be better managed. This is particularly so in resource poor countries where a large population of individuals may not afford all the forms of diagnostic modalities available.

Breast diseases afflict women more than men, the prevalence rate in males ranging from 0 to $5.8 \%$ in most series (1-3). Majority of male breast afflictions are benign with gynaecomastia occupying the top slot $(1,2,4)$. Among females, the distribution of pathology varies widely depending on age and geographical location. Benign lesions predominate at all ages accounting for $48.9 \%$ to $57 \%$ with a mean age of occurrence being 28.5 years $(1,2,6,7)$. Benign lesion prevalence rates can peak $99 \%$ in those younger than 30 years (7). Fibroadenoma is 
the most common lesion at prevalence rates between 34.7 to $67 \%$ of all breast lesions with a peak mean age incidence of $16-25$ years (1-4, $6,10-13)$. Malignancy or inflammatory lesions come second in frequency to fibroadenoma (2, $6,11,12)$. Benign diseases thus, constitute the major work load in any breast clinic, although some studies have shown that malignant conditions predominate $(4,6)$, yet others have found inflammatory lesions to be the most common disease entity (15). This study undertook to examine the pattern of breast pathology presenting at $\mathrm{KNH}$.

\section{Patients and methods}

The breast clinic's records and case files of all patients managed for breast diseases between $1^{\text {st }}$ September 2000 to March $31^{\text {st }} 2003$ were retrospectively reviewed. The $\mathrm{KNH}$ breast clinic was set up in 2000 for the purpose of optimizing the care of breast diseases. It is held once a week and run by consultant surgeons and surgical residents in training. All patients seen at the clinic during the study period with a clinically and/or cytologically, histologically, radiologically diagnosed breast ailment were included in the study. Patients who presented with previously treated or recurrent lesions were excluded.

The age, sex, duration of symptom, pathological diagnosis and treatment methods were evaluated for each patient. Also abstracted from the medical records were the age at onset of menarche for female patients, family history of breast disease and the intial method of establishing the diagnosis. The data were analysed to calculate frequencies, means and standard deviations.

Permission to do the study was granted by the Kenyatta National Hospital Research and Ethics Committee.

\section{Results}

A total of 1172 new cases were seen at the $\mathrm{KNH}$ breast clinic over the two and a half year period, an average of 469 patients per year or 11 new patients per clinic visit. The mean age of these patients was 34.71 years with a range of 1 to 96 years. Table 1 below gives some descriptive demographic characteristics.

Malignant breast lesions accounted for $22 \%$ of all breast diseases. The most common malignancy was ductal carcinoma constituting $91.7 \%$ of all cancerous breast diseases followed by lobular carcinoma at $2.8 \%$ (Table 2a). The majority of patients $(78 \%)$, had benign conditions, fibroadenoma being the single most common diagnosis made. It accounted for up to $40.2 \%$ of benign conditions (Table $2 b$ ) and $33.2 \%$ of all breast ailments put together. Five disease conditions: fibroadenoma, breast abscess, fibrocystic disease, mastalgia and chronic mastitis accounted for $83.4 \%$ of all benign lesions and formed the main work load at the clinic. Out of the 22 patients with chronic mastitis, eight had confirmed tuberculosis of the breast. Males constituted less than $1 \%$ in this series and gynaecomastia was the most common lesion seen in this group (Table 3).

Nine hundred and four patients presented with lumps. In two thirds of this group, the lumps measured more than $5 \mathrm{~cm}$ in their widest diameters. Fine needle aspiration cytology (FNAC) was used in the initial definitive diagnosis in $46.1 \%$ of all cases. Excisional and incisional biopsies were utilised for only 8.6 and $3.0 \%$ of cases respectively. Patients diagnosed purely on clinical assessment comprised $40.0 \%$ (Table 4). Over $80 \%$ of patients seen at the KNH breast clinic were operated upon (Table 5).

\section{Table1: Demographic characteristics}

\begin{tabular}{lcccccc} 
Variable & No. & Mean & Median & Sd & Minimum & Maximum \\
Age (years) & 1172 & 34.71 & 32 & 15.829 & 1 & 96 \\
Duration (months) of symptoms & 920 & 6.86 & & 13.616 & 0.1 & 120 \\
Age at menarche (years) & 700 & 14.49 & 14 & 2.447 & 8 & 21 \\
\hline
\end{tabular}


Table 2a: Distribution of malignant lesions

\begin{tabular}{lcc} 
Diagnosis & Frequency & $(\%)$ \\
Ductal carcinoma & 231 & 91.7 \\
Lobular carcinoma & 7 & 2.78 \\
Malignant phylloides & 6 & 2.38 \\
Poorly differentiated carcinoma & 3 & 1.19 \\
Primary soft tissue sarcoma & 2 & 0.79 \\
Squamous cell carcinoma & 2 & 0.79 \\
Ductal carcinoma with Pagets & 1 & 0.4 \\
\hline Total & 252 & 100 \\
\hline
\end{tabular}

Table 2b: Distribution of benign breast conditions

\begin{tabular}{lcc} 
Diagnosis & Frequency & $(\%)$ \\
\hline Fibroadenoma & 370 & 40.2 \\
Abscess & 173 & 18.8 \\
Fibrocystic disease & 119 & 12.9 \\
Mastalgia( breast pain) & 83 & 9.02 \\
Mastitis chronic & 22 & 2.39 \\
Duct ectasia & 12 & 1.3 \\
Galactocoele & 12 & 1.3 \\
Gynaecomastia & 12 & 1.3 \\
Tubular adenoma & 10 & 1.1 \\
Lipoma & 10 & 1.1 \\
others & 86 & 9.4 \\
Inconclusive & 11 & 1.2 \\
\hline Total & 920 & 100 \\
\hline
\end{tabular}

Table 3: Distribution of male breast pathology

\begin{tabular}{lcc} 
Diagnosis & frequency & $(\%)$ \\
Gynaecomastia & 7 & 36.8 \\
Ductal carcinoma & 4 & 21.1 \\
Fibradenoma & 3 & 15.8 \\
Fibrocystic disease & 2 & 10.5 \\
Chronic abscess & 1 & 5.3 \\
Malignant phylloides & 1 & 5.3 \\
Inconclusive & 1 & 5.3 \\
\hline Total & 19 & 100 \\
\hline
\end{tabular}

Table 4: Mode of initial definitive diagnosis $(n=899)$

\begin{tabular}{lrr} 
Mode of diagnosis & Frequency & $(\%)$ \\
FNAC & 414 & 46.1 \\
Clinical examination & 359 & 40.0 \\
Excisional biopsy & 78 & 8.6 \\
Incisional biopsy & 27 & 3.0 \\
others & 21 & 2.3 \\
\hline Total & 899 & 100 \\
\hline
\end{tabular}

Table 5: Primary treatment offered initially $(n=1114)$

\begin{tabular}{lcr} 
Initial treatment modality offered & Frequency & $(\%)$ \\
Surgery & 903 & 81.1 \\
Reassured & 79 & 7.1 \\
Radiotherapy & 55 & 4.9 \\
Non cancer oral medication & 46 & 4.1 \\
Chemotherapy & 27 & 2.4 \\
Others & 4 & 0.4 \\
\hline Total & 1114 & 100 \\
\hline
\end{tabular}

\section{Discussion}

This study reviewed data of 1172 patients seen at the KNH breast clinic over a two and a half year period. The majority, $98.9 \%$, were females which is consistent with the rarity of male breast disease (prevalence ranges from 0 to $5.8 \%$ ) in most series (1-3). Even then the majority of male breast afflictions are known to be benign, $(2,4)$ as indicated by this study where $73.6 \%(14$ of 19) were benign lesions with gynaecomastia being the commonest diagnosis made. In a retrospective study in Saudi Arabia over a 15year period $(n=63)$, Chiedozi et al found that $87 \%$ of all male breast lesions were benign (1). The same study revealed that gynaecomastia was the most frequently diagnosed condition in males, $54 \%$, and that only $3 \%$ of all breast cancers occurred in the male population.

Overall, fibroadenoma was the single most common diagnosis made followed by ductal carcinoma of the breast. This compares well with other studies where fibroadenoma shows prevalence rates between 34.7 and $67 \%$ of all breast lesions and a peak mean age incidence of 16-25 years $(1-4,6,10-13)$. Five conditions namely fibroadenoma, ductal carcinoma, breast abscesses, fibrocystic disease and breast pain (mastalgia) accounted for over $85 \%$ of all breast ailments seen. These five conditions share similar prominence in other studies, only differing in their order of ranking. Two studies, one in Jordan $(n=1000)$ and the other in Pakistan $(\mathrm{n}=3879)$ found breast cancer to top the list of breast pathologies followed by fibrocystic disease and fibroadenoma in 
respective studies $(4,6)$. In Papua New Guinea inflammatory conditions were the most common type of breast lesions with chronic mastitis and abscesses, constituting 32\% of all breast diseases and $71 \%$ of the mastitides (15). It is imperative that emphasis be placed on the management of these five conditions in both undergraduate and postgraduate training.

Fine needle aspiration cytology (FNAC) was the most commonly used initial pathological diagnostic investigation for breast lumps. This is tandem with worldwide trends $(18,19)$, and the declining role of incisional and excisional biopsy in the initial diagnosis of solid and cystic masses of the breast. FNAC is easy to perform with minimal expertise even in the clinic setting, does not require anaesthesia and is less invasive compared to other methods. However, it requires well trained cytologists in order to reduce false positive or negative results. The correlation between cytology and histology in breast lesions has been studied at $\mathrm{KNH}$ and found to be good (16). Forty percent of lesions were diagnosed on the basis of clinical assessment alone. Presumably, breast abscesses, mastalgia and fibroadenomas in a young population, which comprised a large proportion of the current data set, informed the decisions.

Of the patients presenting with lumps, two thirds had masses greater than $5 \mathrm{~cm}$. This is consistent with the long duration of symptoms in the current study and the the earlier study that denoted that up to $70 \%$ of patients diagnosed with breast cancer have advanced disease at $\mathrm{KNH}$ (17). As an initial means of treatment, over $80 \%$ of patients seen were operated upon with only $7.1 \%$ getting reassurance only. This may seem an excessive initial treatment both for the majority fibroadenomas and the breast malignancies. These two conditions constituted $52.9 \%$ of all breast ailments. Most of the work load in any breastclinicis largely considered to be that of reassuring the "worried well", implying that most pathologies encountered are benign, non-life threatening conditions that should be treated conservatively. Fiboadenomas are benign fibroepithelial tumors that grow slowly, are rarely symptomatic, tend to be bilateral and multiple, do not have predilection to malignancy and up to $40 \%$ may regress within two years. It is unclear whether the decisions to excise them in the current study were influenced by their large sizes (giant fibroadenomas), symptoms, sudden change in biology or patient request. For the advanced malignant lesions, the place of neoadjuvant therapy is now advocated. It is possible that this form of initial therapy was neither accessible nor available for the cohort. Further studies to evaluate our breast surgery practice are recommended.

\section{Acknowledgements}

To the management of Kenyatta National Hospital for allowing us to access the hospital records and granting permission to publish this paper.

\section{References}

1. Chiedozi L.C., El-Hag I.A. and Kollur S.M. Breast Diseases in the northern region of Saudi Arabia. Saudi Med. J. 2003; 6: 623-627.

2. Jamal A.A. Pattern of breast diseases in a teaching hospital in Jeddah, Saudi Arabia. Saudi Med. J. 2001; 2: 110-113.

3. Adesunkanmi A.R. and Agbakwuru E.A. Benign breast diseases at Wesley Guild Hospital, Ilesha Nigeria. West Afr. J. Med. 2001; 2: 146-151.

4. Chaudhuri M., Sens, and Sengupta J. Breast lumps: A study of 10 years. J. Indian Med. Assoc. 1995; 12: 455-457.

5. Adeniji K.A., Adelusola K.A. and Odesanmi W.O. Benign disease of the breast in Ile-Ife: A 10 year experience and literature review. Central Afr. J. Med. 1997; 5: 140-143.

6. Mansoor I. Profile of female breast lesions in Saudi Arabia. J. Pak. Med. Assoc. 2001; 7: 243-247.

7. Raju G.C., Jankey N. and Naraynsingh V. Breast disease in young West Indian women: an analysis of 1051 consecutive cases. Post Grad. Med. J. 1985; 721: 977-978.

8. El-Tamer M.B., Jong M. and Wait R.B. Breast diseases in African American teenage girls. J. Padiatr. Surg. 1999; 9: 1401-1404.

9. Amr S.S. Breast diseases in Jordanian females: a study of 1000 cases. Eur. J. Surg. Oncol. 1985; 3: 257-262.

10. Mc Farlane M.E. Benign breast diseases in AfroCaribbean population. East Afr. Med. J. 7: 538-539. 
11. Oluwole S.F. and Freeman H.P. Analysis of benign breast lesions in blacks. Amer. J. Surg. 1979; 6: 786-789.

12. Raju G.C. and Naraynsingh V. Benign breast disease in a West Indian Population. Brit. J. Surg. 1985; 1: 17-18.

13. Bjerregaard B. and Kungu A. Benign breast lesions in Kenya: A histological study. East Afr. Med. J. 1992; 5: 231-235.

14. Mbinde M.P., Amir H., Mbembati N.A., et al. Characterization of benign lesions and carcinomas of the female breast in a Sub-Saharan African population. Pathol. Res. Pract. 1998; 9: 623-629.

15. Murthy D.P., Senhupta S.K. and Muthaiah A.C. Benign breast disease in Papua New Guinea. PNG. Med. J. 1992; 2: 101-105.
16. Muchiri L.W., Penner D.W., Adwok J. et al. Role of fine-needle aspiration biopsy in the diagnosis of breast lumps at the Kenyatta National Hospital. East Afr. Med. J. 1993; 70 (4 Suppl): 31-33.

17. Othieno Abinya N.A., Nyabola L.O., Abwao H.O. et al. Post-surgical management of patients with breast cancer at Kenyatta National Hospital. East Afr. Med. J. 2002; 79: 156-162.

18. Mamoon N., Mushtaq S., Rashid M., et al. The value of fine needle aspiration biopsy in the management of breast disease. J. Pak. Med. Assoc. 1995; 45(5): 120-122.

19. Khatun H., Tareak-Al-Nasir, Enam S., et al. Correlation of fine needle aspiration cytology and its histopathology in diagnosis of breast lumps. Bangladesh Med. Res. Counc. Bull. 2002; 28(2): 77-81. 